\title{
Astragaloside IV protects cardiomyocytes against hypoxia injury via HIF-1 $\alpha$ and the JAK2/STAT3 pathway
}

\author{
Bei $\mathrm{Li}^{1} \wedge$, Junjian $\mathrm{Yu}^{2}$, Peipei Liu ${ }^{1}$, Taohui Zeng ${ }^{1}$, Xueliang Zeng ${ }^{1}$ \\ ${ }^{1}$ Department of Pharmacy, First Affiliated Hospital of Gannan Medical University, Ganzhou, China; ${ }^{2}$ Cardiovascular and Thoracis Surgery \\ Department 2, First Affiliated Hospital of Gannan Medical University, Ganzhou, China \\ Contributions: (I) Conception and design: X Zeng; (II) Administrative support: B Li, J Yu; (III) Provision of study materials or patients: P Liu; (IV) \\ Collection and assembly of data: T Zeng; (V) Data analysis and interpretation: B Li, J Yu; (VI) Manuscript writing: All authors; (VII) Final approval \\ of manuscript: All authors. \\ Correspondence to: Xueliang Zeng. Department of Pharmacy, First Affiliated Hospital of Gannan Medical University, Ganzhou, China. Email: \\ zengxueliang2021@163.com.
}

Background: Hypoxia is an important cause of myocardial injury due to the heart's high susceptibility to hypoxia. Astragaloside IV (AS-IV) is the main component of Astragalus membranaceus and could exert cardiac protective role. Here, the effect of AS-IV on hypoxia-injured H9c2 cardiomyocytes was elucidated.

Methods: First, H9c2 cells were exposed to hypoxia and/or AS-IV treatment. Cell apoptosis, death, and viability as well as bypoxia-inducible factor $1 \alpha(H I F-1 \alpha)$ expression and apoptotic proteins were analyzed. Next, transfection of si-HIF-1 $\alpha$ into H9c2 cells was carried out to test whether upregulation and stabilization of $H I F-1 \alpha$ influences the effect of AS-IV on hypoxia-treated H9c2 cells. Furthermore, the regulatory role of fanus kinase 2/signal transducer and activator of transcription 3 (FAK2/STAT3) signaling on HIF-1 $\alpha$ levels was examined.

Results: Hypoxia suppressed viability and promoted the apoptosis and death of H9c2 cells. AS-IV eliminated hypoxia-induced H9c2 injury. Moreover, $H I F-1 \alpha$ signaling was further activated and stabilized by AS-IV in hypoxia-challenged H9c2 cells. Downregulation of HIF-1 $\alpha$ suppressed the function of AS-IV in hypoxia-challenged H9c2 cells. AS-IV promoted $7 A K 2 / S T A T 3$ signaling in hypoxia-induced injury. The beneficial functions of AS-IV in hypoxia-exposed H9c2 cells were linked to HIF-1 $\alpha$ upregulation and $7 A K 2 /$ STAT3 signaling activation.

Conclusions: AS-IV relieved H9c2 cardiomyocyte injury after hypoxia, possibly by activating $\mathcal{Z} A K 2 /$ STAT3-mediated HIF-1 $\alpha$ signaling.

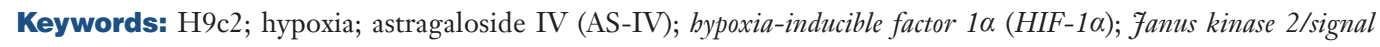
transducer and activator of transcription 3 signaling (7AK2/STAT3 signaling)

Submitted Jul 20, 2021. Accepted for publication Sep 18, 2021.

doi: 10.21037/atm-21-4080

View this article at: https://dx.doi.org/10.21037/atm-21-4080

\section{Introduction}

Cardiovascular disease (CVD) is a public health crisis that accounts for $>30 \%$ of all deaths globally (1). Cardiovascular conditions induced by hypoxia, such as myocardial infarction, peripheral vascular disease, stroke, and renal ischemia, contribute to high mortality and disability rates (2). In particular, apoptosis and death of cardiomyocytes are common in many forms of CVD (3). COVID-19 is an ongoing pandemic caused by severe acute respiratory syndrome coronavirus-2 (SARS-CoV-2)

\footnotetext{
$\wedge$ ORCID: 0000-0003-0633-0193.
} 
infection (4,5). Myocardial injury has been described in many patients with COVID-19 $(6,7)$. Hypoxia itself is one of the main mechanisms of COVID-19-related myocardial injury (8). Thus, experimental and clinical research is urgently needed to determine the molecular basis of hypoxia-induced cardiomyocyte injury and to identify effective treatments.

Astragaloside IV (AS-IV), 3-O-beta-d-xylopyranosyl-6O-beta-d-glucopyranosyl-cycloastragenol $\left(\mathrm{C}_{14} \mathrm{H}_{68} \mathrm{O}_{14}\right)$, is extracted from the dried roots of Astragalus membranaceus (9) and was approved by the Chinese Pharmacopeia 2010 (10). Previous studies have shown that AS-IV has antiinflammatory (11), anti-viral (12), and anti-oxidative effects (13). In a rat aortic banding model, AS-IV prevented hypertrophy by increasing autophagy and inhibiting inflammation (14). In neonatal rat cardiomyocytes, AS-IV protected against hypoxia/reoxygenation (H/R)induced injury by enhancing protein kinase $\mathrm{A}(P K A)$ and Ser(16) phosphorylated phospholamban [Ser(16)-PLN] expression (15). AS-IV pretreatment also attenuated anoxia/reoxygenation (A/R) injury by improving $\mathrm{B}$ cell lymphoma-2 ( $B c l$-2)-mediated mitochondrial function in both in vitro and in vivo experiments (16). Furthermore, the compatibility of tanshinone IIA and AS-IV restored H9c2 cell survival by inhibiting stress-responsive generic mitogenactivated protein kinase (MAPK) signaling and enhancing serine/threonine kinase 1 (AKT) phosphorylation (17). AS-IV might exert its treatment role via regulating calcium homeostasis and anti-apoptosis and anti-oxidation effect (18). AS-IV has calcium antagonistic role, inhibits calcium overload and restores myocardial calcium pumps activity (19). AS-IV could also promote angiogenesis via VEGF activation (20). Currently, the pathomechanism of AS-IV in hypoxia-triggered damage is not sufficiently understood.

Hypoxia-inducible factor-1 (HIF-1) comprises HIF-1 $\alpha$ and $H I F-1 \beta$ that act as transcriptional mediators in response to hypoxia (21). The levels of HIF-1 increase under decreased oxygen pressure. Its upregulation enhances erythropoiesis, modulation of vascular tone, glycolysis, and angiogenesis (22). Past studies have shown a significant increase in $H I F-1 \alpha$ in tunnel positioning areas surrounding the infarct in human ischemic heart tissues and heart failure (HF) post-acute myocardial infarction (AMI) rats $(22,23)$. There have also been reports showing that $H I F-1 \alpha$ activation mediated through prolyl 4-bydroxylase-2 (PHD2) gene silencing by siRNA treatment attenuates myocardial ischemia-reperfusion injury (IRI) (24). In a rabbit model of IRI, stimulation of HIF-1 $\alpha$ upregulated heme oxygenase 1 (HO-1) levels, which attenuated proinflammatory cytokine production (25). Thus, stabilizing HIF-1 $\alpha$ increases myocardial tissue tolerance to ischemia-induced injury.

Signal transducer and activator of transcription 3 (STAT3) is stimulated by fanus kinase 2 ( $7 A K 2$ )-mediated phosphorylation and modulates cell growth and differentiation. In vivo experiments indicate that STAT3 can subvert the negative effects associated with ischemia on reactive oxygen species and the electron transport chain in MLS-STAT3E mice (26). In vitro evidence has also shown that in glioma cells (U-87MG and U-138MG), HIF$1 \alpha$, p-STAT3, and p- $\mathcal{A} A K$ are reduced by EGF, latrophilin, and seven transmembrane domain containing 1 (ELTD1) knockdown. Further co-immunoprecipitation data showed that p-STAT3 binds to HIF-1a (27). Previous studies have demonstrated that the $\mathcal{F} A K 2 / S T A T 3 / H I F-1 \alpha$ axis is implicated in osteoclastogenesis (28), angiogenesis (29), neuroprotection (30), and anti-tumorigenesis (31).

There is limited data on the benefits of AS-IV in cardiovascular tissues and the effect on $7 A K 2 / S T A T 3 / H I F-$ $1 \alpha$ signaling in hypoxia. Here, we evaluated the impact of AS-IV on hypoxia-related damage to the rat cardiac muscle cell line $\mathrm{H} 9 \mathrm{c} 2$, and its underlying mechanisms. We present the following article in accordance with the MDAR reporting checklist (available at https://dx.doi.org/10.21037/ atm-21-4080).

\section{Methods}

\section{Cell culture and hypoxia cell model}

H9c2 cells were purchased from the National Collection of Authenticated Cell Cultures and passaged in DMEM-H medium (Gibco, New York, NY, USA) enriched with 10\% FBS (Gibco), 2 mM glutamine (Gibco), $100 \mathrm{U} / \mathrm{mL}$ streptomycin (Beyotime, Shanghai, China), and $100 \mathrm{U} / \mathrm{mL}$ penicillin (Beyotime) in a humidified incubator at $37^{\circ} \mathrm{C}$, $5 \% \mathrm{CO}_{2}$. To induce injury, $\mathrm{H} 9 \mathrm{c} 2$ cells were passaged in a hypoxic incubator with $1 \% \mathrm{O}_{2}, 5 \% \mathrm{CO}_{2}$, and $94 \% \mathrm{~N}_{2}$ for the indicated durations. Cells grown in normoxic conditions $\left(21 \% \mathrm{O}_{2}\right)$ were used as controls.

\section{Cell transfection}

Specific siRNAs targeting rat $H I F-1 \alpha$ siRNA (si-HIF-1 $\alpha)$ and negative control siRNA (si-NC) were obtained from RiboBio (Guangzhou, China) and transfected into 
H9c2 cells at $100 \mathrm{nM}$ using Exfect transfection reagent (Vazyme, Nanjing, China) according to the manufacturer's instructions. Briefly, H9c2 cells $\left(2 \times 10^{5}\right)$ were grown in 6-well plates for $24 \mathrm{~h}$. Exfect transfection reagent was added to serum-free media followed by incubation for $5 \mathrm{~min}$ at room temperature (RT). The diluted siRNA was gently mixed with medium containing Exfect transfection reagent and allowed to incubate for $15 \mathrm{~min}$ at RT before adding the mixture to each well containing $80 \%$ confluent cells and medium. The transfected cells were grown under $37^{\circ} \mathrm{C}$ and $\mathrm{CO}_{2}$ conditions for $24 \mathrm{~h}$ prior to downstream experiments.

\section{$A S-I V$ and $A G 490$ treatment}

AS-IV (Shyuanye, Shanghai, China) and AG490 (MedChemExpress, Shanghai, China) were diluted in DMSO. H9c2 cells were challenged with AS-IV (12.5 $\mu \mathrm{M})$ and AG490 $(5 \mu \mathrm{M})$ individually or in combination under normoxic/hypoxic conditions for the indicated durations.

\section{Cell survival analysis}

H9c2 cell survival was assessed using the Cell Counting Kit-8 assay (CCK-8, Dojindo, Shanghai, China). H9c2 cells $(100 \mu \mathrm{L})$ were grown at $2 \times 10^{4}$ cells $/ \mathrm{mL}$ in 96 -well plates overnight. After treatment, $100 \mu \mathrm{L}$ of media enriched with $10 \%$ CCK- 8 solution was added to the cells through media exchange modes. After $1 \mathrm{~h}$ of incubation, absorbance was measured at $450 \mathrm{~nm}$ on a microplate reader (Molecular Devices, San Jose, CA, USA). Each experiment was performed was repeated at least 6 times. The cell survival rate was expressed as a percentage of the control.

\section{Calcein-AM/propidium iodide (PI) staining}

After different treatments, the cells were rinsed twice using $1 \times$ buffer. Then, each group of cells were reconstituted in $1 \times$ assay buffer and stained with $2 \mu M$ calcein-AM (Dojindo, Shanghai, China) and $5 \mu$ M PI (Dojindo, Shanghai, China) per well and incubated at $37{ }^{\circ} \mathrm{C}$ for $30 \mathrm{~min}$ protected from light. Representative images were then captured on the IX73 fluorescence microscope (Olympus, Tokyo, Japan).

\section{Immunocytochemistry analysis}

For immunocytochemistry, 4\% PFA (Boster, Wuhan, China) was used to fix cells at $4{ }^{\circ} \mathrm{C}$ for 30 min followed by permeabilization with $0.5 \%$ Triton $\mathrm{X}-100$ (Beyotime) for
$15 \mathrm{~min}$. Subsequently, non-specific blocking was performed with $2 \%$ BSA (Beyotime) at $4{ }^{\circ} \mathrm{C}$ for $1 \mathrm{~h}$, followed by incubation with anti-HIF-1 $\alpha$ (ab179483, Abcam, Cambridge, UK) at 1:500 overnight at $4{ }^{\circ} \mathrm{C}$. Next, the cells were subjected to another incubation with DyLightFluor ${ }^{\circledR}$ 555 -conjugated donkey anti-rabbit IgG secondary antibody (A0453, Beyotime) at 1:500 for $1 \mathrm{~h}$ at RT and counterstained with DAPI (Sigma-Aldrich, St. Louis, MO, USA) at $10 \mathrm{ng} / \mathrm{mL}$ in the dark for $15 \mathrm{~min}$. Finally, imaging was performed immediately on an Olympus IX73 microscope.

\section{Assessment of cell apoptosis}

An Annexin V-FITC/PI apoptosis kit (Keygentec, Nanjing, China) was used for cell staining and flow cytometry following the manufacturer's instructions. Briefly, cells from each group were washed twice with PBS and $2 \times 10^{5}$ cells were reconstituted in $500 \mu \mathrm{L}$ of binding buffer. Immediately after, $5 \mu \mathrm{L}$ of Annexin V-FITC was added and mixed well. This was followed by the addition of $10 \mu \mathrm{L}$ PI and incubation for $5 \mathrm{~min}$ at RT in the dark in preparation for apoptosis analysis on an Accuri C6 flow cytometer (BD Biosciences, San Jose, CA, USA).

\section{Isolation of total RNA and real-time PCR}

The TRIzol reagent (Vazyme) was utilized for RNA extraction followed by cDNA synthesis with a reverse transcription kit (Vazyme). The reverse transcription PCR (RT-PCR) assay was then performed on a CFX96 system (Bio-Rad Laboratories, Hercules, CA, USA) with the following parameters: denaturation at $95{ }^{\circ} \mathrm{C}$ for $10 \mathrm{~min}, 40$ cycles of denaturation at $95{ }^{\circ} \mathrm{C}$ for $15 \mathrm{~s}$, annealing at $60^{\circ} \mathrm{C}$ for $20 \mathrm{~s}$, and extension at $72{ }^{\circ} \mathrm{C}$ for $25 \mathrm{~s}$. The $2^{-\triangle \Delta C T}$ method was used to determine mRNA levels. The PCR was based on the indicated primers: HIF-1 $\alpha$ (forward: $5 '$-atgtaccctaacaagccggg-3', reverse: $5^{\prime}$-acaaatcagcaccaagcacg-3'), $\beta$-actin (forward: 5'-cccatctatgagggttacgc-3', reverse: 5'-tttaatgtcacgcacgatttc-3'). All the primers were obtained from by Generay Bioengineering (Shanghai, China).

\section{Protein extraction and western blot assay}

Briefly, we used RIPA buffer (Beyotime) to lyse cells for protein extraction following the manufacturer's instructions. After separation with $10 \%$ SDS-PAGE and transfer to 


\section{Page 4 of 15}

PVDF membranes (Millipore, Billerica, MA, USA), the membranes were then blocked using 5\% BSA (Beyotime) for $1 \mathrm{~h}$ and incubated with the indicated antibodies at $4{ }^{\circ} \mathrm{C}$ overnight: HIF-1 $\alpha$ (ab179483, 1:1,000), Bcl-2 (ab196495, 1:1,000), Bax (ab32503, 1:5,000) (all from Abcam), caspase-3 (14220, 1:1,000), fAK2 (3230, 1:1,000), p- fAK2 (3776, 1:1,000), STAT3 (9139, 1:1,000), p-STAT3 (9145, 1:2,000) (all from Cell Signalling Technology, Boston, MA, USA), and $\beta$-actin (AF0003, 1:2,000, Beyotime). After washing with TBST thrice (10 min each), the membrane was probed with HRP-conjugated anti-rabbit IgG (A0208, Beyotime) or anti-mouse IgG (A0216, Beyotime) secondary antibodies at RT for $1 \mathrm{~h}$ and washed thrice with TBST. The signal was then developed using ECL (Beyotime) and imaged on a chemiluminescence detection system (Bio-Rad Laboratories). Band intensities were analyzed by Image J.

\section{Statistical analysis}

All the experiment were repeated three times. All data are shown as mean \pm SD and were analyzed with Graphpad Prism 5.0. Comparisons between groups were assessed using Student's $t$-test. $\mathrm{P}<0.05$ indicated statistical significance.

\section{Results}

\section{Hypoxia triggers injury in $\mathrm{H} 9 \mathrm{c} 2$ cells}

Cell survival, cell death, apoptosis, and western blot assays were conducted to elucidate the impact of hypoxia. Sustained hypoxia treatment significantly decreased the cell survival rate, as the survival was only $31.6 \% \pm 7.1 \%$ after $72 \mathrm{~h}$ (Figure 1A). The representative images of calceinAM/PI staining showed that hypoxia treatment markedly enhanced cell death in H9c2 cells (Figure 1B). Additionally, hypoxia treatment significantly induced $\mathrm{H} 9 \mathrm{c} 2$ cell apoptosis compared with the normoxia-treated group (Figure 1C). The expression levels of apoptosis-related proteins also changed markedly, with the $B c l-2 / B a x$ ratio reduced and cleaved caspase-3 levels elevated by hypoxia (Figure 1D). These effects of hypoxia on cells were time-dependent.

\section{Hypoxia alters HIF-1 $\alpha$ protein level in $\mathrm{H} 9 \mathrm{c} 2$ cells}

HIF-1 $\alpha$ modulates responses to hypoxia (32). Compared with the normoxic group, $6 \mathrm{~h}$ of hypoxia treatment significantly increased $H I F-1 \alpha$ levels. However, HIF-1 $\alpha$ levels did not consistently increase after hypoxia treatment
Li et al. Astragaloside protects cardiomyocytes against hypoxia

for 12-48 h, but gradually fell. Immunocytochemistry analysis results were consistent with the western blot findings (Figure $2 A, 2 B$ ).

\section{AS-IV suppresses hypoxia-induced injury and upregulates HIF-1a levels in $\mathrm{H} 9 \mathrm{c} 2$ cells in a sustained way}

Hypoxia triggers H9c2 cell injury (33). The CCK-8 assay showed that treatment with AS-IV $(12.5 \mu \mathrm{M})$ timedependently improved the survival rate of hypoxia-exposed H9c2 cells (Figure 3A). Next, we assessed how AS-IV affects $H I F-1 \alpha$ expression in $\mathrm{H} 9 \mathrm{c} 2$ cells challenged with hypoxia for 6 and $48 \mathrm{~h}$. We observed that relative to normoxic controls, HIF-1 $\alpha$ levels were sharply elevated upon $6 \mathrm{~h}$ of hypoxic injury and were markedly reduced after $48 \mathrm{~h}$. Interestingly, after treatment of $\mathrm{H} 9 \mathrm{c} 2$ cells subjected to hypoxia for 6 or $48 \mathrm{~h}$ with AS-IV $(12.5 \mu \mathrm{M})$, HIF-1 $\alpha$ levels remained elevated relative to the normoxic and hypoxiaonly groups. Immunocytochemistry results were consistent with the western blot findings (Figure 3B,3C).

\section{Downregulation of HIF-1a represses $A S-I V$-mediated protection against hypoxic damage}

To examine whether HIF-1 $\alpha$ has an essential role in AS-IVmediated protection of hypoxic injury, HIF-1 $\alpha$ was inhibited using siRNA in H9c2 cells. It was confirmed that siRNA2 efficiently suppressed $H I F-1 \alpha$ expression using quantitative RT-PCR (RT-qPCR) and western blot analyses. Thus, we chose HIF-1 $\alpha$ siRNA2 for subsequent cytology experiments (Figure $4 A, 4 B$ ). At $24 \mathrm{~h}$ after siRNA transfection, ASIV $(12.5 \mu \mathrm{M})$ treatment was simultaneously performed when H9c2 cells were placed under hypoxic conditions at specified time points ( 6 and $48 \mathrm{~h}$ ). Western blot and immunocytochemistry results revealed that the $H I F-1 \alpha$ level in the $\mathrm{NC}+$ hypoxia + AS-IV group was significantly higher than in the si-HIF-1 $\alpha+$ hypoxia + AS-IV group (Figure $4 C, 4 D$ ). Similarly, there were corresponding findings in the next series of experiments. The cell survival rate was apparently lower, while cell death and apoptosis were discernibly higher in the si-HIF-1 $\alpha+$ hypoxia + ASIV group compared to the NC + hypoxia + AS-IV group (Figure 4E-4G). To confirm this result, we assessed the expression levels of apoptosis-related proteins in all samples. The western blot results showed that the level of cleaved caspase-3 was visibly increased, while the ratio of $B c l-2 /$ Bax was significantly decreased in the si-HIF-1 $\alpha+$ hypoxia + AS-IV group compared to the NC + hypoxia + AS-IV 
A

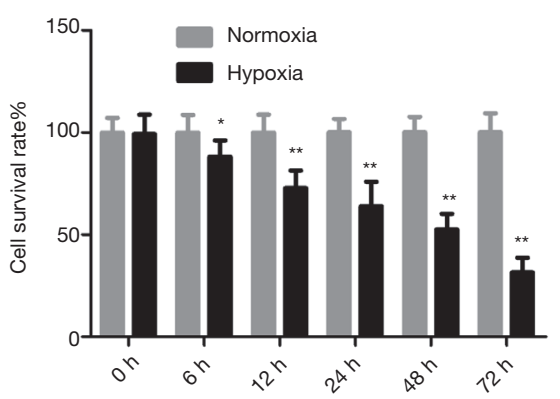

C

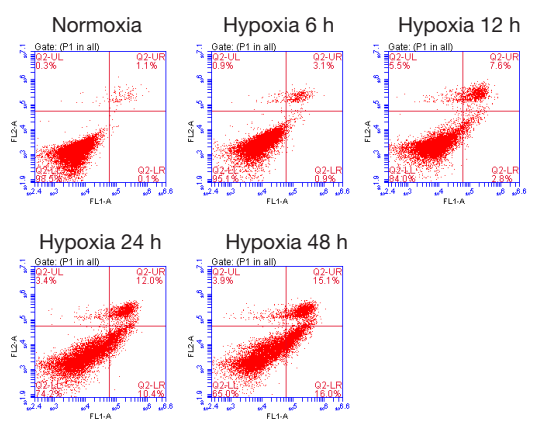

D

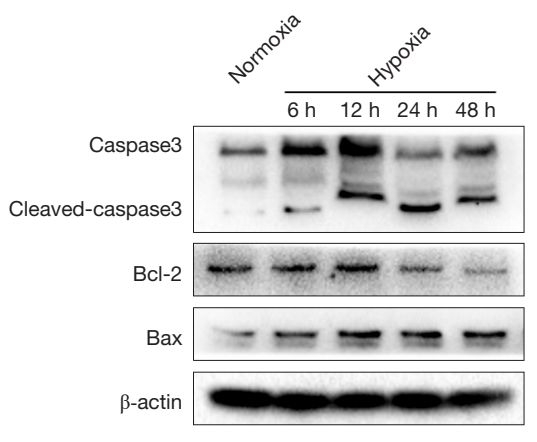

B
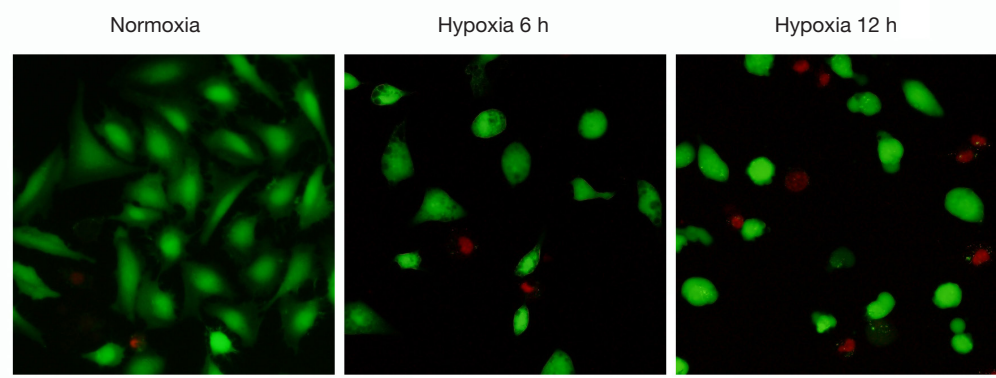

$\mathrm{H} 9 \mathrm{C} 2$

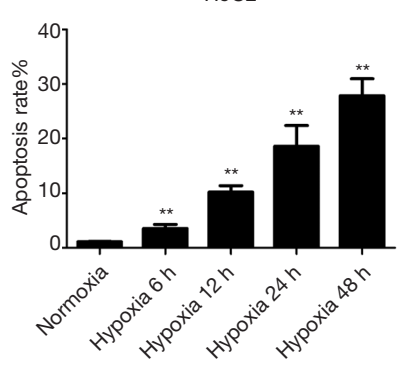

Hypoxia $24 \mathrm{~h}$
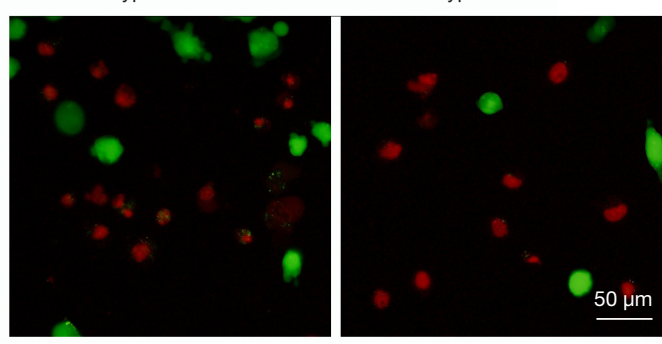

$\mathrm{Bcl}-2 / \mathrm{Bax}$
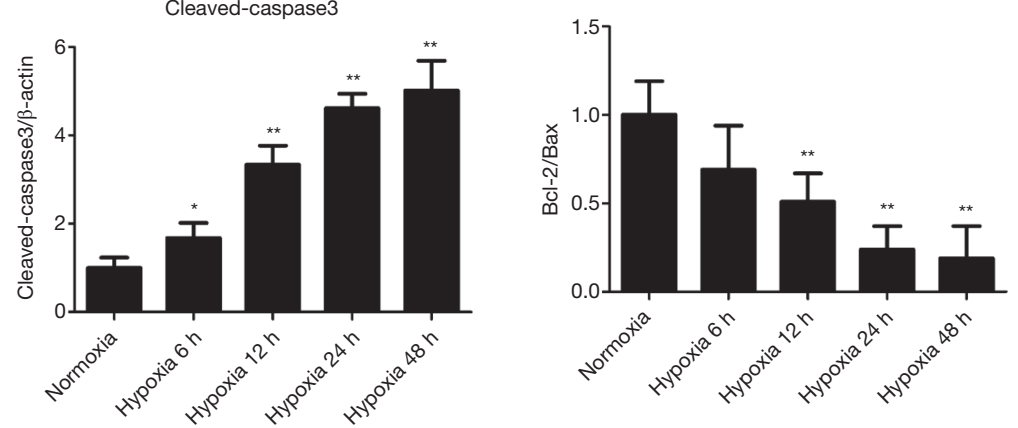

Figure 1 Hypoxia causes hypoxic injury in H9c2 cells. The effects of hypoxia on H9c2 cells were examined by assaying cell survival, apoptosis, calcein-AM/PI staining, and apoptosis-related proteins. (A) The H9c2 cell survival rate was determined after exposure to hypoxia for the indicated periods. (B) Cell death was detected using calcein-AM (green) and PI (red) staining. (C) Apoptosis was evaluated using flow cytometry. (D) Western blot analysis of the levels of the apoptotic proteins cleaved caspase-3, Bcl-2, and Bax. $\beta$-actin was used as the loading control. Results are shown as mean $\pm \mathrm{SD}$ of three independent experiments performed in duplicate. ${ }^{*} \mathrm{P}<0.05$ or ${ }^{* *} \mathrm{P}<0.01$ vs. normoxia group. PI, propidium iodide.

group (Figure 4H). The results described above indicate that $H I F-1 \alpha$ silencing blocks AS-IV-mediated protection under hypoxic conditions.

\section{$A S-I V$ prevents hypoxic injury of $H 9 c 2$ cells by regulating FAK2/STAT3/HIF-1a signaling}

7AK2 phosphorylates STAT3 and activates the $7 A K 2 / S T A T 3$ pathway (34). To test whether $7 A K 2 / S T A T 3$ signaling mediates hypoxia-induced injury in cardiomyocytes, the phosphorylation levels of $7 A K 2$ and STAT3 were measured. This analysis revealed that $\mathrm{p}-S T A T 3$ and $\mathrm{p}-\mathcal{F A K 2}$ levels consistently fell after hypoxia treatment for 6 and $48 \mathrm{~h}$, while AS-IV $(12.5 \mu \mathrm{M})$ restored and even increased their levels (Figure $5 A$ ). To confirm these findings, we suppressed the $7 A K 2 / S T A T 3$ pathway using AG490 $(5 \mu \mathrm{M})$, a $7 A K 2$ inhibitor (35), and assessed p-STAT3, STAT3, p- $\mathcal{F A K 2}, \mathcal{F} A K 2$, and HIF-1 $\alpha$ expression by western 
A

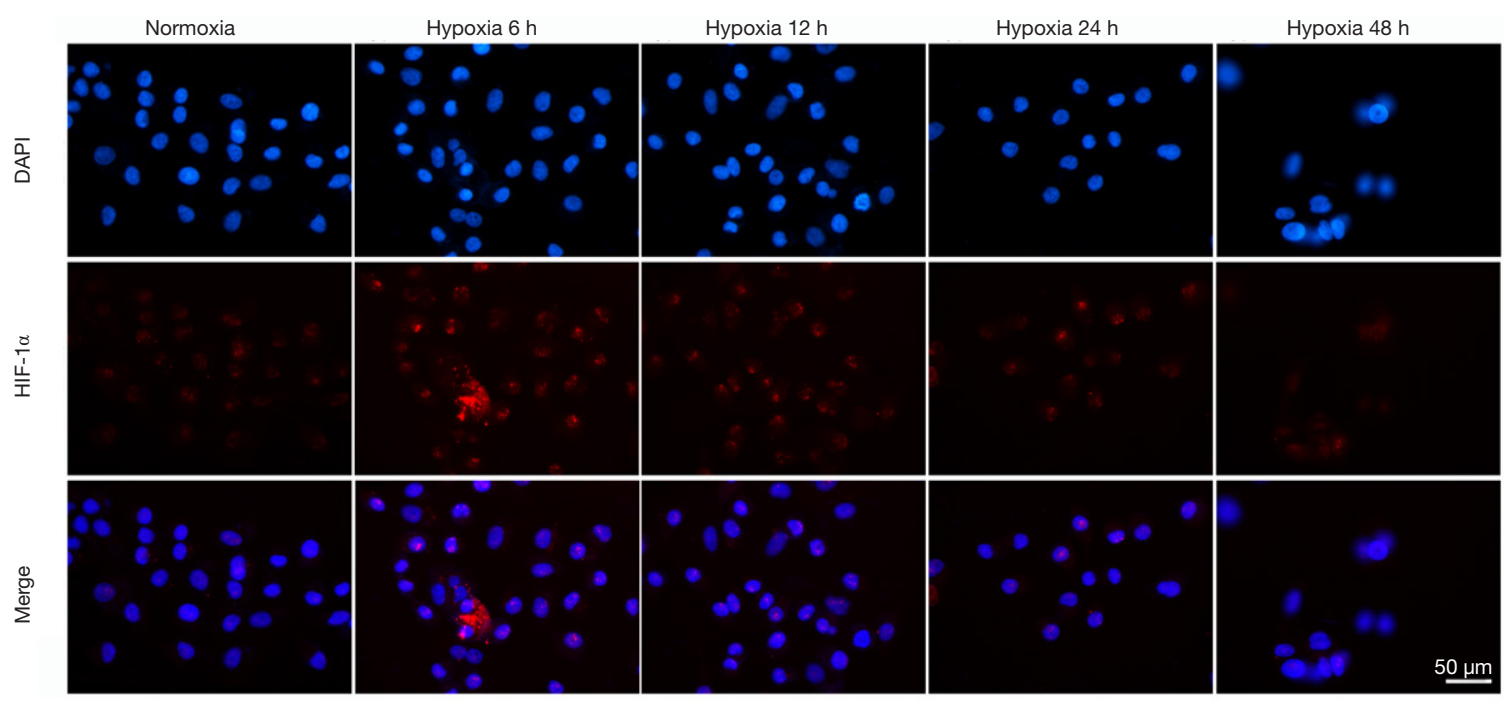

B
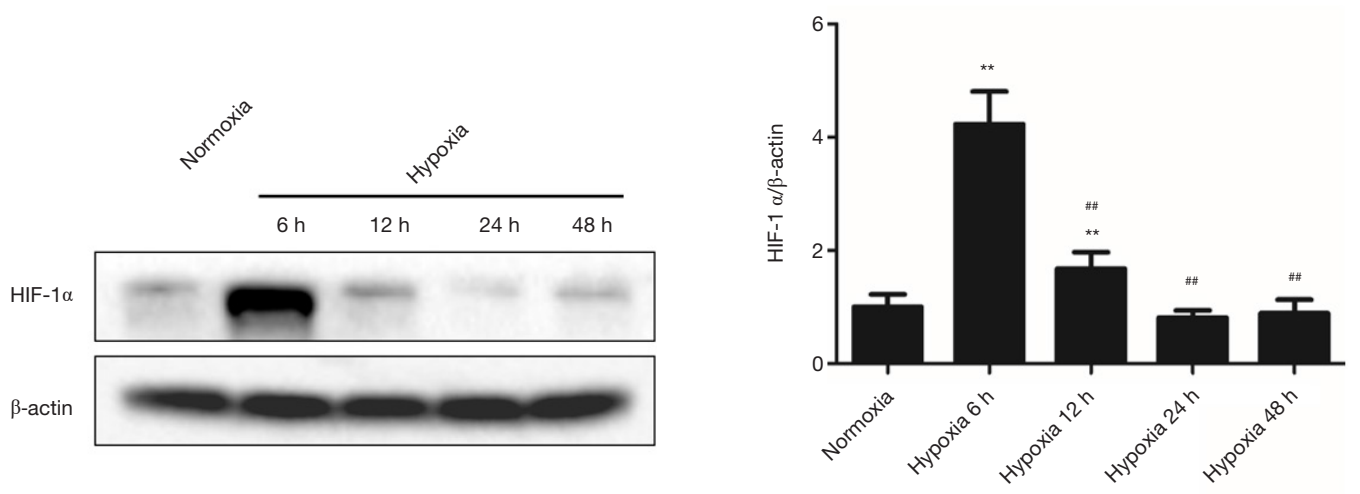

Figure $2 H I F-1 \alpha$ protein levels in response to hypoxia induction. (A,B) HIF-1 $\alpha$ levels were measured using immunocytochemistry and western blot after exposure to hypoxia for the indicated periods. Results are mean $\pm \mathrm{SD}$ of three independent experiments performed in

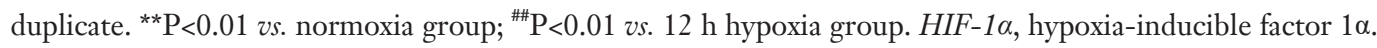

blot. The western blot analysis revealed a marked reduction of $\mathrm{p}-\mathrm{FAK} 2$ and $\mathrm{p}-S T A T 3$ expression in the hypoxia + AS-IV + AG490 group relative to the hypoxia + ASIV group (Figure 5B). Moreover, HIF-1 $\alpha$ protein levels followed the same trend (Figure $5 B$ ). The corresponding immunocytochemistry observation of $H I F-1 \alpha$ expression strengthened the western blot results (Figure 5C). These findings suggested that AS-IV promotes HIF-1 $\alpha$ expression and stability by regulating upstream factors like p- $\mathcal{A} A K 2$ and p-STAT3. The CCK- 8 assay revealed that the cell survival rate in the hypoxia + AS-IV group was obviously increased relative to the hypoxia + AS-IV + AG490 group at both 6 and $48 \mathrm{~h}$ (Figure 5D). The degree of cell death and apoptosis and the expression of apoptosis-related proteins in the hypoxia + AS-IV group were much lower than the hypoxia + AS-IV + AG490 group (Figure 5E-5G). Together, these data demonstrate that AG490 suppresses the benefits of AS-IV on hypoxic damage by blocking the fAK2/STAT3/ HIF-1 $\alpha$ signaling pathway.

\section{Discussion}

CVD claims many lives worldwide. Oxygen is crucial to the metabolism and survival of aerobic cells. Oxygen tension influences numerous cellular processes, including proliferation, cell differentiation, glycolysis, apoptosis, angiogenesis, and gene expression. Severe hypoxia may cause apoptosis and even necrosis. Previous study found angiogenesis is critical in the recovery of myocardial ischemia. AS-IV could regulate angiogenesis and HIF-1 $\alpha$ 

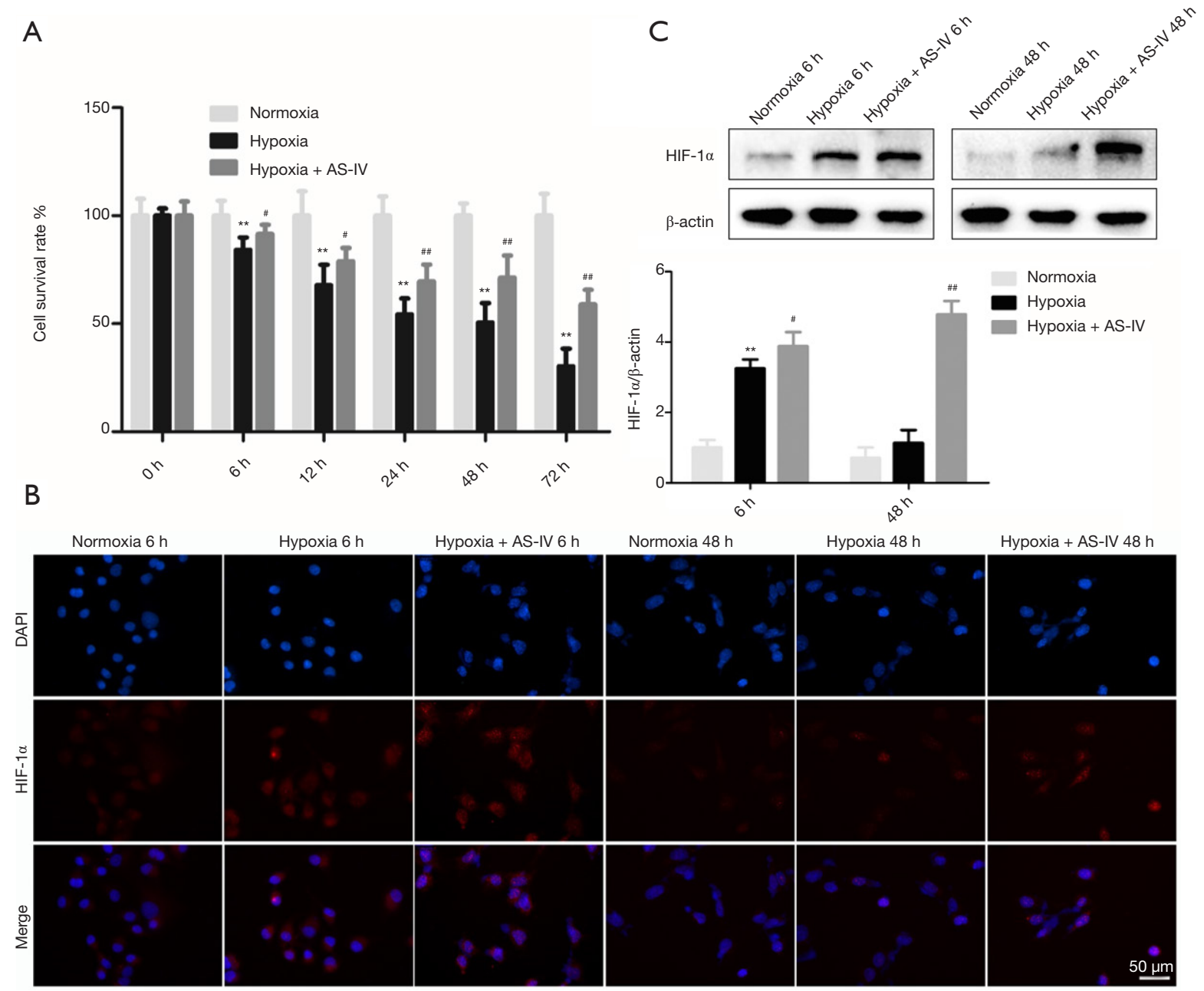

Figure 3 The effects of AS-IV treatment on hypoxic injury and HIF-1 $\alpha$ protein expression. (A) The H9c2 cell survival rate was determined after exposure to hypoxia and AS-IV treatment for the indicated durations. (B,C) $H I F-1 \alpha$ protein levels were determined by immunocytochemistry and western blot after exposure to hypoxia and AS-IV treatment for the indicated durations. Results are mean \pm SD of three independent experiments performed in duplicate. ${ }^{* *} \mathrm{P}<0.01$, hypoxia group vs. normoxia group; ${ }^{\#} \mathrm{P}<0.01$ or ${ }^{\# \#} \mathrm{P}<0.01$, hypoxia + ASIV group vs. hypoxia group. AS-IV, astragaloside IV; HIF-1 $\alpha$, hypoxia-inducible factor $1 \alpha$.

level in human umbilical vein endothelial cells via PI3K/ Akt pathway (36). Hypoxia induces $H I F-1 \alpha$ expression, and its expression level in the nucleus depends on the balance between its ubiquitination and small ubiquitinrelated modifier (SUMO) modification (37). The expression of SUMO1 could stabilize the HIF-1 $\alpha$. AS-IV could promote the expression of SUMO1. Thus, the treatment of AS-IV might promote angiogenesis via promoting the level of SUMO1 and the stabilization of HIF-1a (38). Cardiomyocytes are the main functional cells in pumping blood. Cardiomyocyte injury by hypoxia is a cause of several ischemic heart disorders (39). Here, we examined how AS-IV affects hypoxia-induced damage of H9c2 cells. Our data show that AS-IV stimulated and stabilized $H I F-1 \alpha$ expression in $\mathrm{H} 9 \mathrm{c} 2$ cells challenged with hypoxia. $H I F-1 \alpha$ upregulation contributed to the effects of AS-IV on enhancing viability and reducing the apoptosis of $\mathrm{H} 9 \mathrm{c} 2$ cells under hypoxic conditions. Our data also indicate that AS-IV enhanced the activation of $7 A K 2 / S T A T 3$ signaling, which upregulated $H I F-1 \alpha$ in $\mathrm{H} 9 \mathrm{c} 2$ cells.

Myocardial tissue has very limited innate regenerative capacity, and there are no myocardial tissue regeneration strategies available. Thus, myocardial injury is irreversible (40). Cardiomyocyte injury is mainly caused by cardiomyocyte 
A

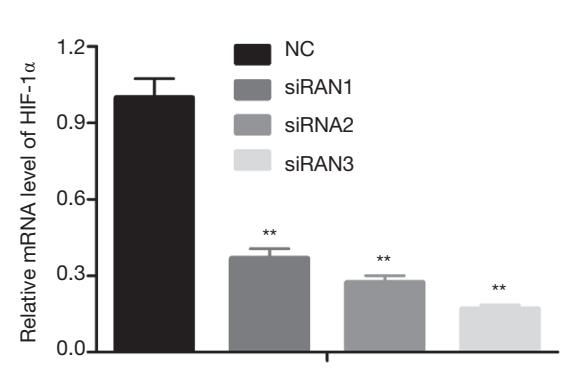

B

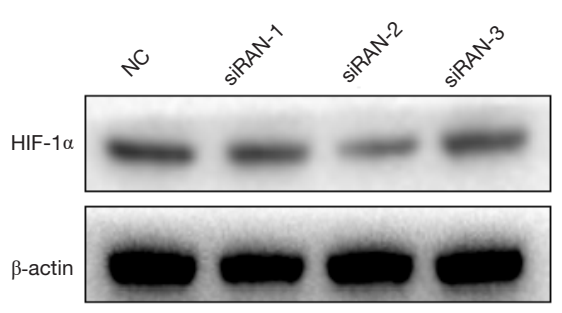

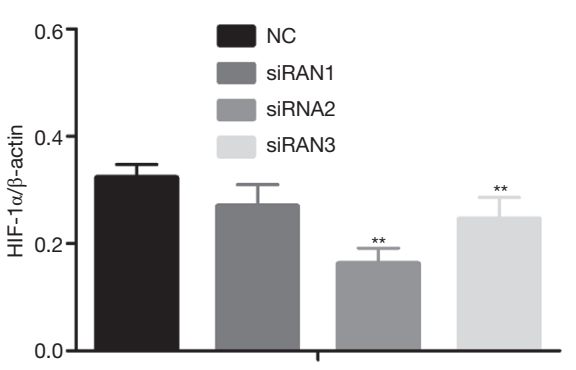

C
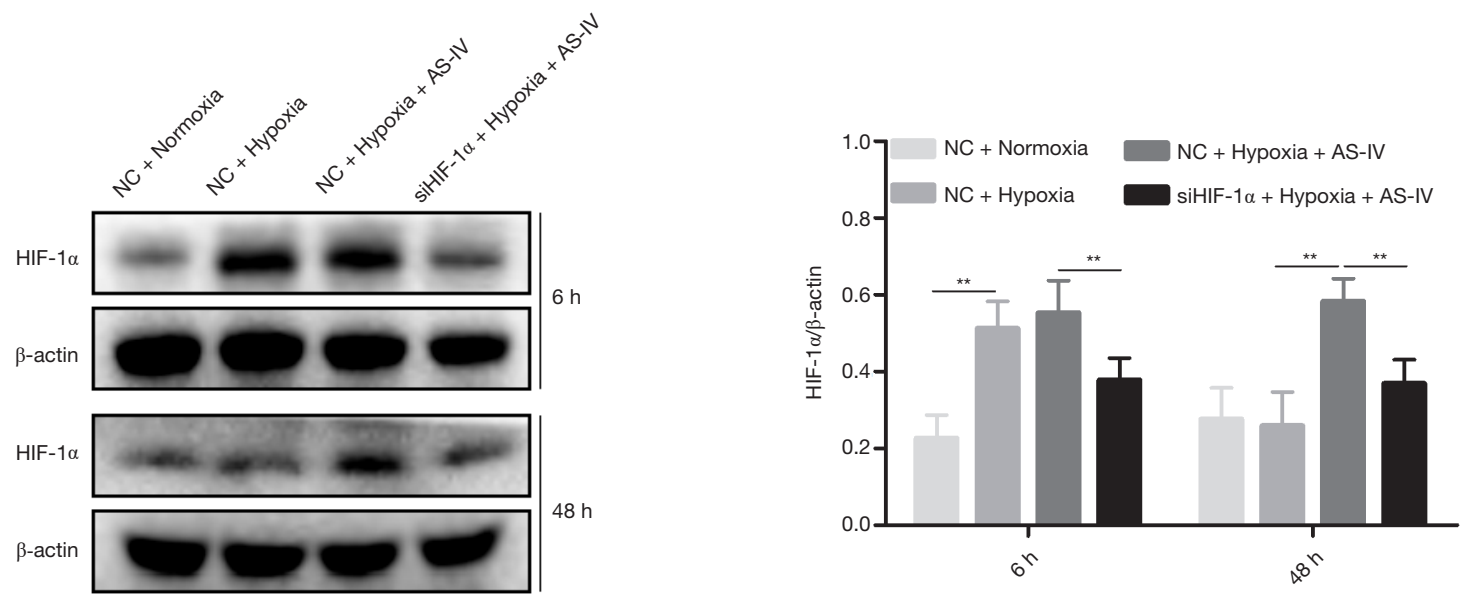

D

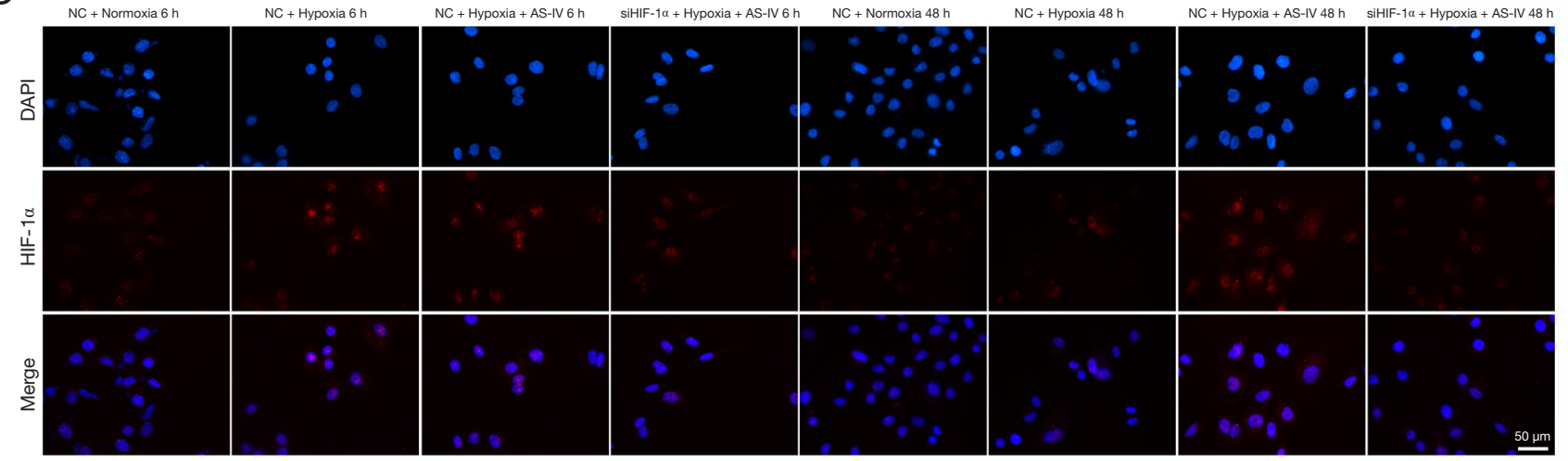

E

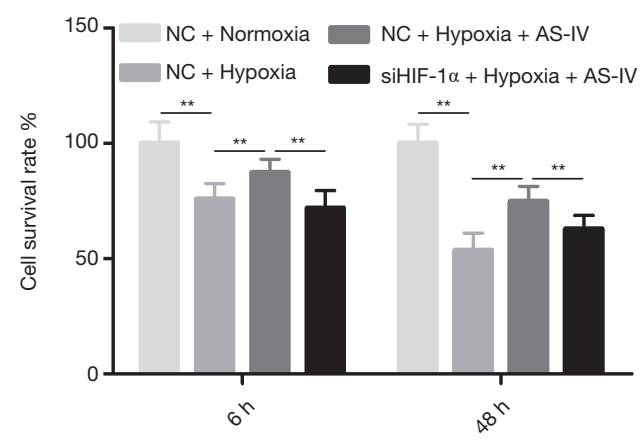

F

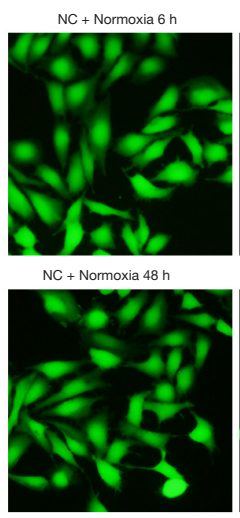

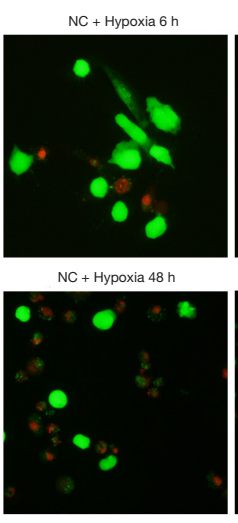
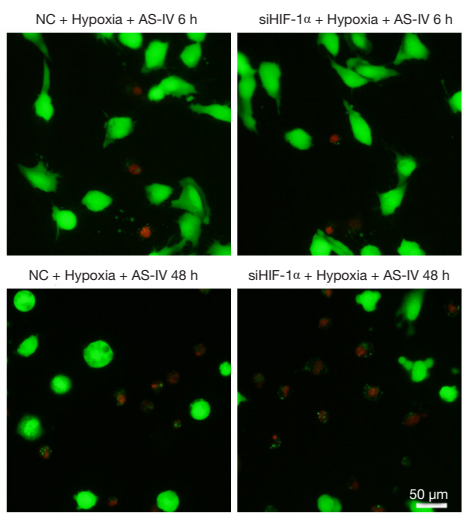
G
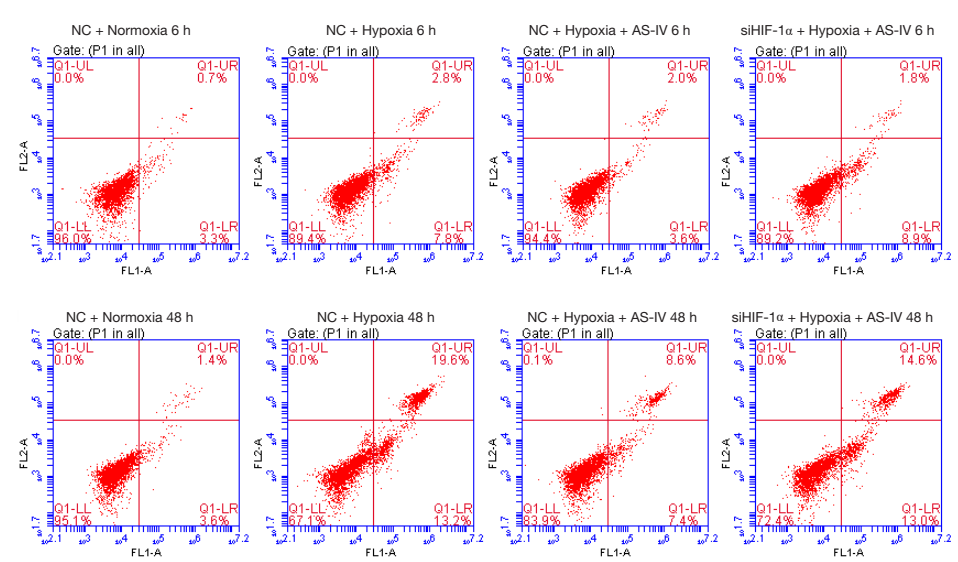

$\mathrm{H}$

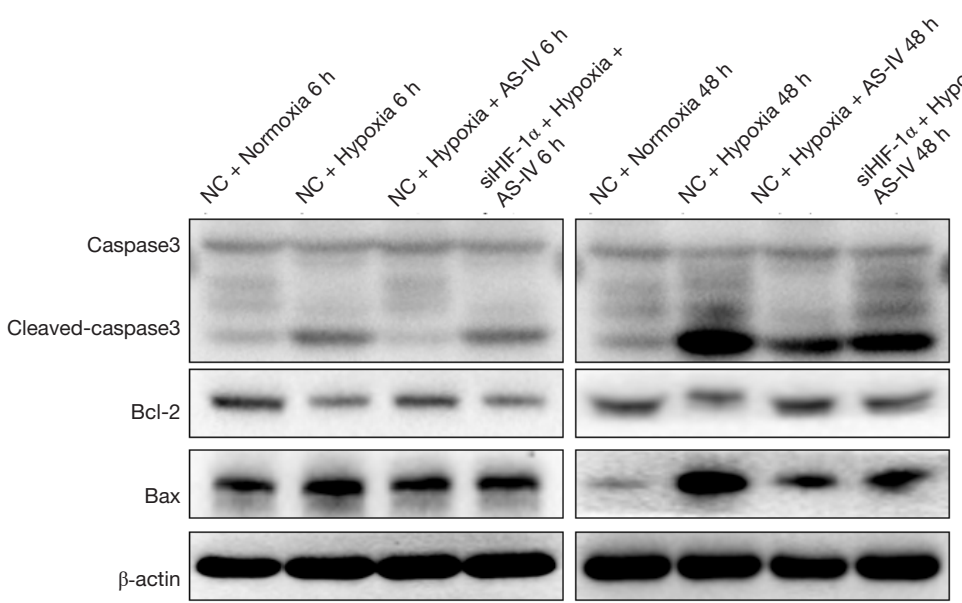

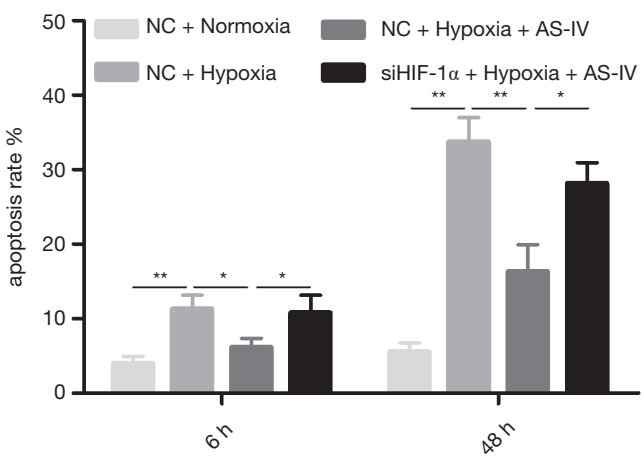
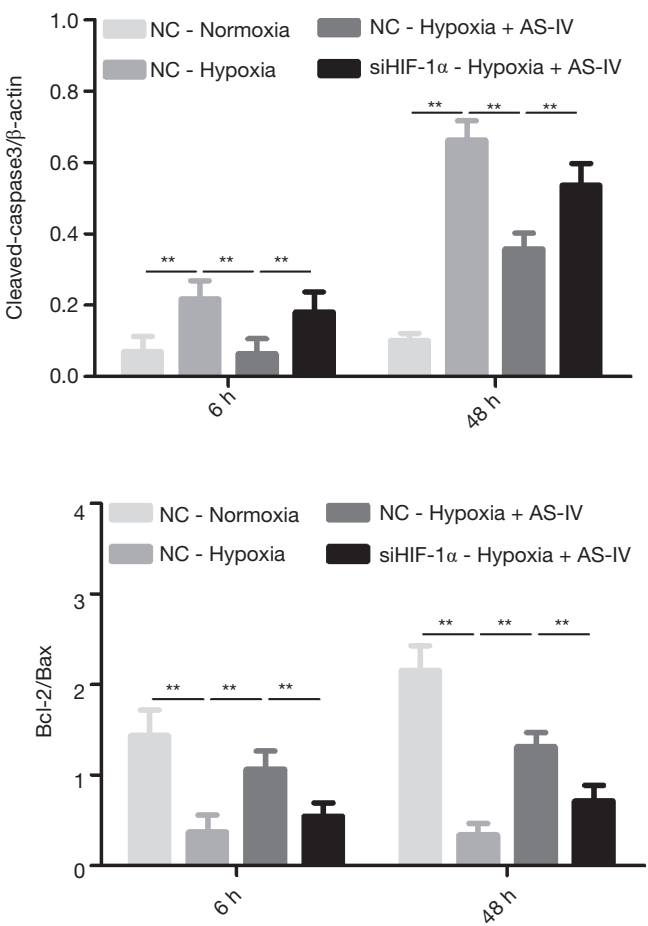

Figure 4 The protective effects of AS-IV on hypoxic injury were suppressed by HIF-1 $\alpha$ downregulation. (A,B) RT-qPCR and western blot analysis of HIF-1 $\alpha$ expression in H9c2 cells transfected with si-HIF-1 $\alpha$ or control si-NC. (C,D) HIF-1 $\alpha$ protein levels after siRNA transfection, and the effects of hypoxia and AS-IV treatment were determined by immunofluorescence and western blot analyses. (E) Cell survival was measured using the CCK-8 assay. (F) Cell death was assayed by calcein-AM/PI staining. (G) Apoptosis was assayed by flow cytometry. $(\mathrm{H})$ Western blot analysis of the levels of the apoptotic proteins cleaved caspase-3, Bcl-2, and Bax. $\beta$-actin was used as the loading control. Results are mean $\pm \mathrm{SD}$ of three independent experiments performed in duplicate. ${ }^{*} \mathrm{P}<0.05$ or ${ }^{* *} \mathrm{P}<0.01$ vs. corresponding group. ASIV, astragaloside IV; HIF-1 $\alpha$, hypoxia-inducible factor $1 \alpha$; RT-qPCR, quantitative reverse transcription PCR; si-HIF-1 $\alpha, H I F-1 \alpha$ siRNA; siNC, negative control siRNA; CCK-8, Cell Counting Kit-8; PI, propidium iodide.

apoptosis. Here, we exposed H9c2 cells to hypoxia to establish an in vitro model of myocardial injury and tested cell viability, apoptosis, and death. Our data show that hypoxia stimulates cell damage and apoptosis, and transiently upregulates $H I F-1 \alpha$.

As-iv is one of the main active components of Astragalus membranaceus. AS-IV can reduce the apoptosis of neurons after intracerebral hemorrhage (41) and reduce the area of myocardial infarction (42). AS-IV has been widely used to treat cardiovascular, liver, kidney, and skin diseases in China (43). AS-IV is a therapeutic agent with a variety of activities and a potential therapeutic role in myocardial 
A
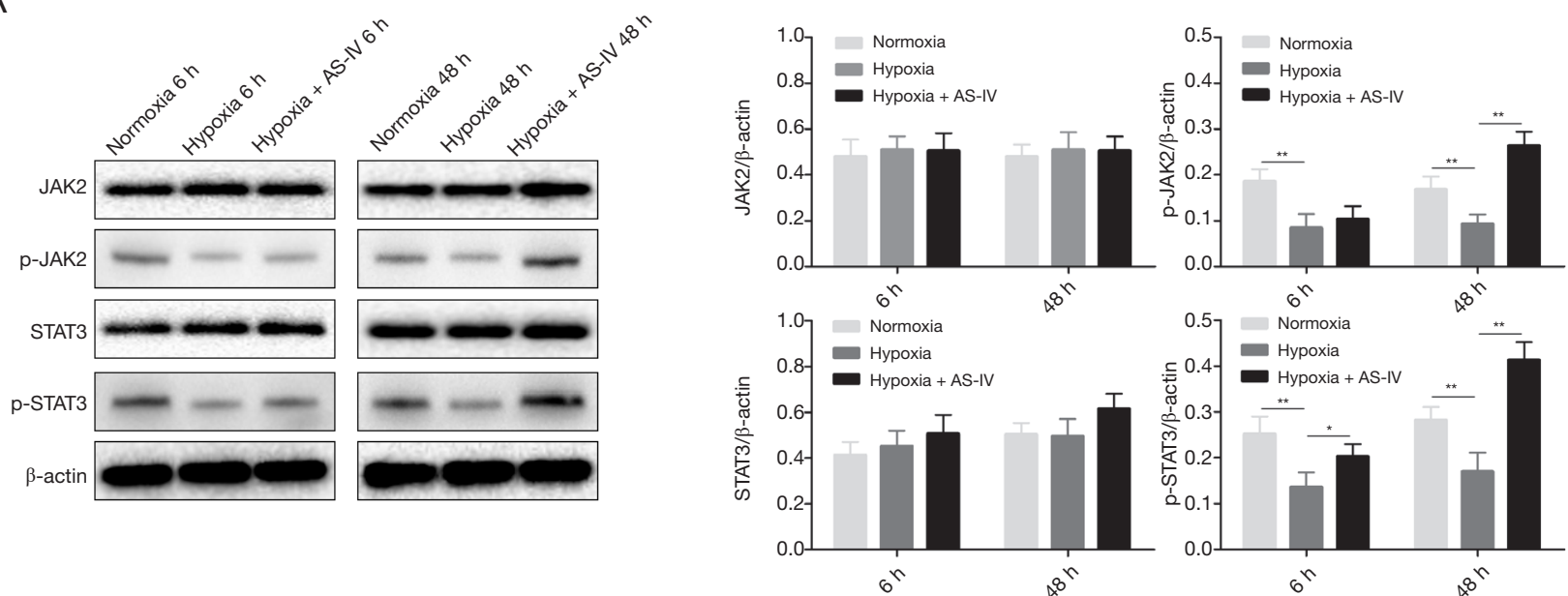

B
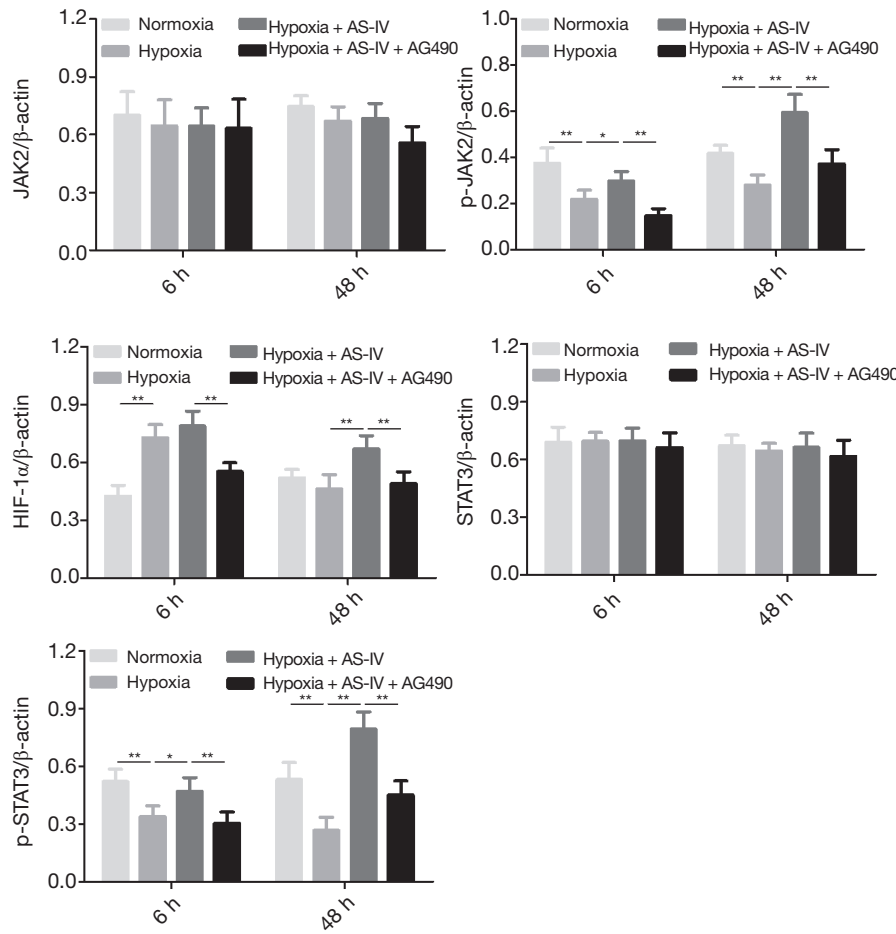

C
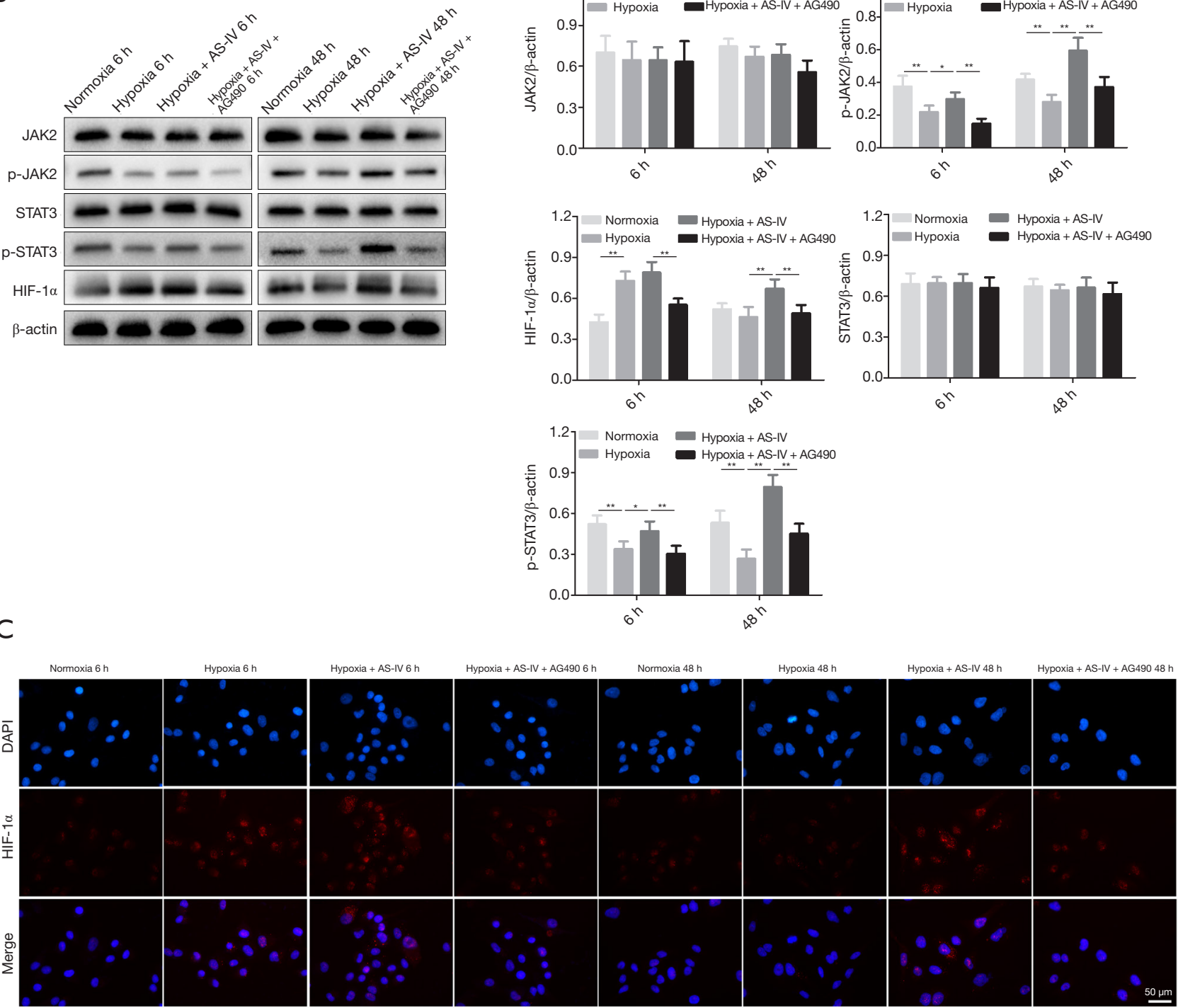
D

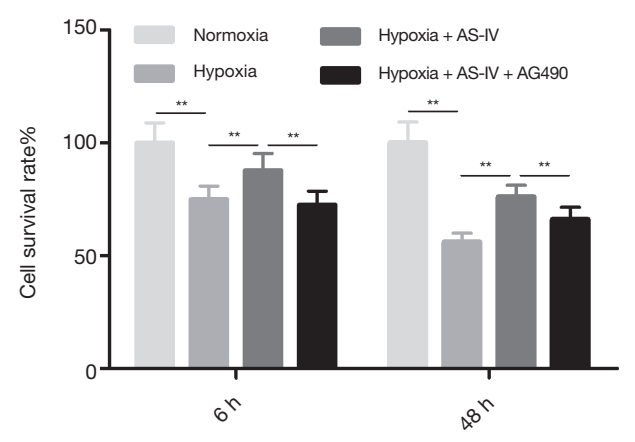

$\mathrm{E}$

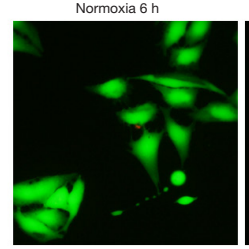

Normoxia $48 \mathrm{~h}$

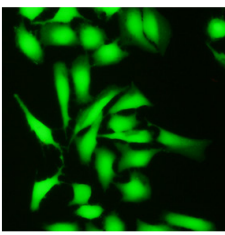

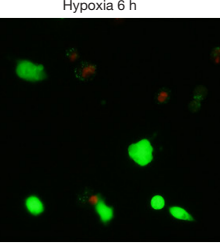

Hypoxia $48 \mathrm{~h}$

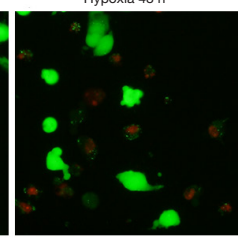

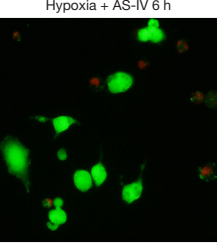

Hypoxia + AS-IV $48 \mathrm{~h}$

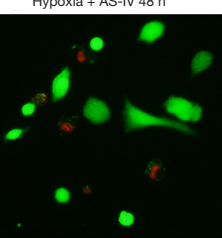

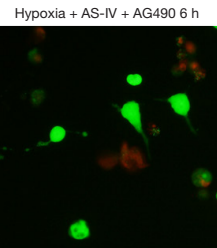

Hypoxia + AS-1V+ AG490 $48 \mathrm{~h}$

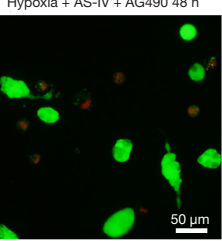

$\mathrm{F}$
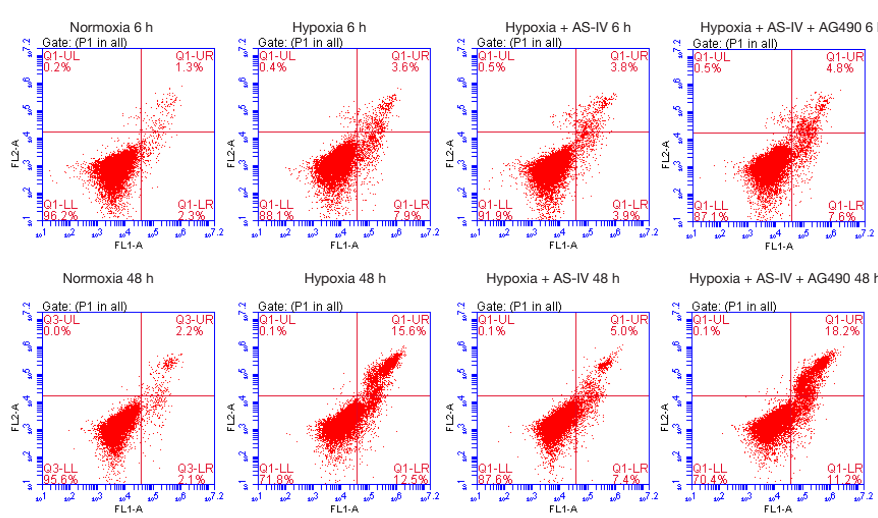

Hypoxia + AS-IV + AG490 $48 \mathrm{~h}$
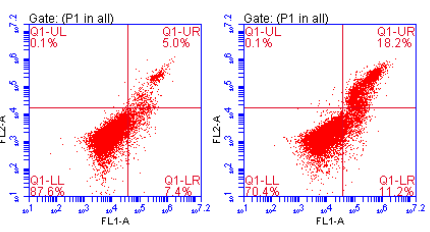

G

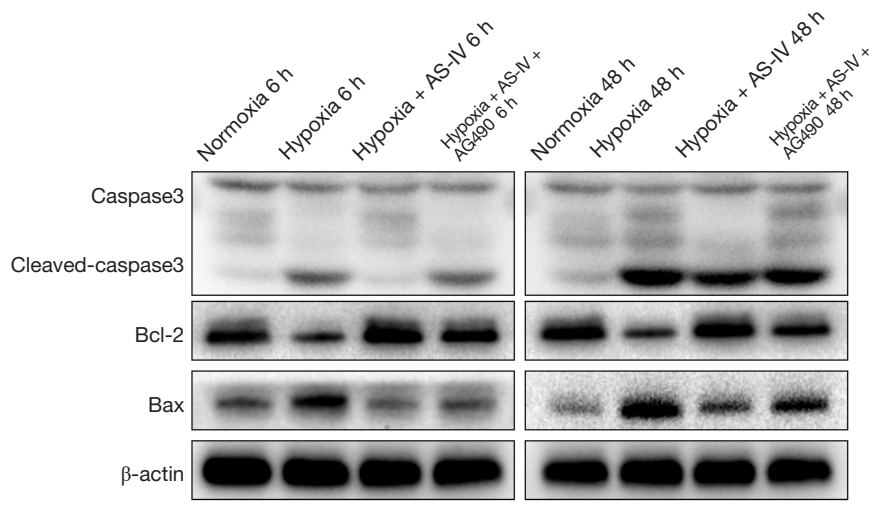

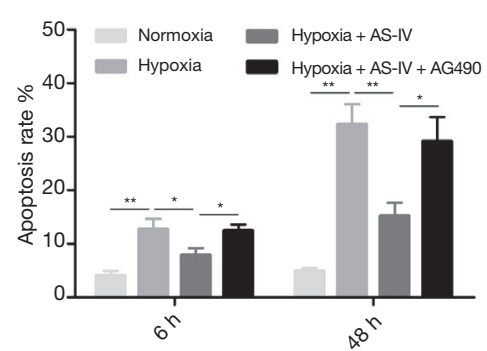
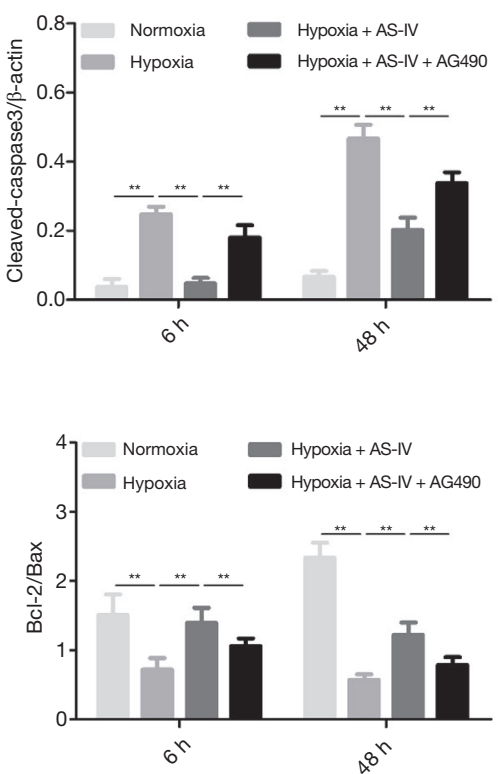

Figure 5 Influence of $7 A K 2-S T A T 3$ signaling on the protective effects of AS-IV against hypoxic injury. (A) Western blot analysis of FAK2/p- $7 A K 2$ and STAT3/p-STAT3 expression after exposure to hypoxia and AS-IV treatment for the indicated durations. (B) Western blot analysis of $7 A K 2 / \mathrm{p}-7 A K 2$, STAT3/p-STAT3, and HIF-1 $\alpha$ expression after exposure to hypoxia, AG490, and AS-IV for the indicated durations. (C) After the corresponding treatment, HIF-1 $\alpha$ expression changes were detected by immunocytochemistry. (D) Cell survival was evaluated using the CCK-8 assay. (E) Cell death was detected using calcein-AM/PI staining. (F) Apoptosis was evaluated by flow cytometry. (G) Western blot analysis of the apoptotic proteins cleaved caspase-3, Bcl-2, and Bax. $\beta$-actin was used as the loading control. Results are mean $\pm \mathrm{SD}$ of three independent experiments performed in duplicate. ${ }^{*} \mathrm{P}<0.05$ or ${ }^{* *} \mathrm{P}<0.01$ vs. corresponding group. FAK2, Janus kinase 2; STAT3, signal transducer and activator of transcription 3; AS-IV, astragaloside IV; HIF-1 $\alpha$, hypoxia-inducible factor 1 $\alpha$; CCK-8, Cell Counting Kit-8; PI, propidium iodide. 


\section{Page 12 of 15}

protection. Besides AS-IV, there are other drugs could protect cardiomyocytes against hypoxia damage, like Dimethyl malonate (44), chloramphenicol succinate (45), mitochondrial division inhibitor-1 (46), miR-499 (47) and rapamycin (48). Astragalus membranaceus is a traditional drug that widely used in China for thousand years. AS-IV is the main component of Astragalus membranaceus. ASIV has great treatment potential and is relatively easy to transfer to clinical application.

Past findings show that AS-IV relieves H9c2 cardiomyocyte damage under hypoxic conditions by modulating miRNAs (49), lncRNAs (50), $\mathrm{Ca}^{2+}$ homeostasis (51), and $\mathrm{PI} 3 \mathrm{~K} / \mathrm{AKT} / \mathrm{HO}-1$ signaling (52). Evidence has also showed As-IV can exert myocardial protective role via PI3K/ AKT/GSK-3 $\beta$ pathway (53). The angiogenesis could also be regulated by AS-IV via PTEN/PI3K/Akt pathway (54). Here, we found that $H I F-1 \alpha$ was increased and hypoxiainduced injury were decreased hypoxia model with treatment of $12.5 \mu \mathrm{M}$ AS-IV.

$H I F-1 \alpha$ is a key transcription factor that controls adaptive responses to hypoxia by regulating downstream target genes (55). HIF-1 $\alpha$ could induce the expression of iNOS. The level of iNOS is upregulated in cardiomyocytes after hypoxia treatment. INOS pathway could be activated by AS-IV induced HIF-1 $\alpha$ activation (56). Normally, $H I F-1 \alpha$ activity depends on the amount of $H I F-1 \alpha$ protein, which is markedly upregulated by hypoxia. However, the $H I F-1 \beta$ protein is constitutively expressed in cells regardless of oxygen tension (57). HIF-1 $\alpha$ protein levels are determined by a balance between protein synthesis and degradation. $H I F-1 \alpha$ protects against oxygen-glucose deprivation/reperfusion (OGD/R) injury by upregulating the expression of $B C L 2 /$ adenovirus E1B $19 \mathrm{kDa}$ proteininteracting protein 3 (Bnip3) in H9c2 cells (58). Ubiquitinconjugating enzyme E2S (UBE2S) protected against apoptosis after myocardial ischemia/reperfusion (MI/R) injury, which might have contributed to the activation of $H I F-1 \alpha$ (59). In the present study, HIF-1 $\alpha$ was shown to be upregulated in the presence of AS-IV treatment.

FAK2/STAT3 is an important signaling pathway involved in hypoxia/ischemia and oxidative stress in various tissues and organs, as well as having protective roles in hypoxic and ischemic injury (60). Past studies show that STAT3 acts

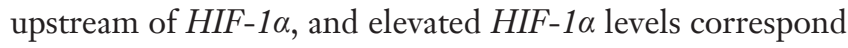
with elevated STAT3 phosphorylation $(61,62)$. A mouse model of myocardial ischemia revealed that myocardial cell apoptosis and the area of myocardial infarction were

\section{Li et al. Astragaloside protects cardiomyocytes against hypoxia}

significantly increased by IRI after treatment with AG490. To confirm whether $7 A K 2 / S T A T 3 / H I F-1 \alpha$ signaling mediated hypoxia-induced injury in cardiomyocytes, we silenced HIF-1 $\alpha$ using siRNA and inhibited $7 A K 2 / S T A T 3$ phosphorylation with AG490 and found that AS-IV protection was weakened in the hypoxia model.

In conclusion, our data show that $H I F-1 \alpha$ expression is upregulated by short exposure to hypoxia. In contrast, this change was reduced by prolonged modeling time and aggravated cell injury. However, upon treatment with AS-IV under hypoxic conditions, HIF-1 $\alpha$ expression was upregulated and stabilized. Furthermore, analysis of FAK2/STAT3 signaling activation suggested that AS-IV positively regulates $H I F-1 \alpha$ by enhancing $7 A K 2 / S T A T 3$ phosphorylation. In contrast, genetic silencing of HIF-1a and blocking of $7 A K 2 / S T A T 3$ signaling by AG490 resulted in the inhibition of the protective effect of AS-IV. Together, these findings indicate that AS-IV protects $\mathrm{H} 9 \mathrm{c} 2$ cells from hypoxic injury by modulating $7 A K 2 / S T A T 3 / H I F-1 \alpha$ signaling. Our findings may provide initial theoretical support for the study of the regulatory mechanism of ASIV in hypoxia-induced cardiomyocyte injury, and suggest innovative therapeutic strategies for the treatment of CVDs.

\section{Acknowledgments}

Funding: The work was financially supported by Science and Technology Research Project of Jiangxi Provincial Department of Education (Project No. GJJ201541).

\section{Footnote}

Reporting Checklist: The authors have completed the MDAR reporting checklist. Available at https://dx.doi. org/10.21037/atm-21-4080

Data Sharing Statement: Available at https://dx.doi. org/10.21037/atm-21-4080

Conflicts of Interest: All authors have completed the ICMJE uniform disclosure form (available at https://dx.doi. org/10.21037/atm-21-4080). The authors have no conflicts of interest to declare.

Ethical Statement: The authors are accountable for all aspects of the work in ensuring that questions related to the accuracy or integrity of any part of the work are 
appropriately investigated and resolved.

Open Access Statement: This is an Open Access article distributed in accordance with the Creative Commons Attribution-NonCommercial-NoDerivs 4.0 International License (CC BY-NC-ND 4.0), which permits the noncommercial replication and distribution of the article with the strict proviso that no changes or edits are made and the original work is properly cited (including links to both the formal publication through the relevant DOI and the license). See: https://creativecommons.org/licenses/by-nc-nd/4.0/.

\section{References}

1. Benjamin EJ, Blaha MJ, Chiuve SE, et al. Heart disease and stroke statistics-2017 update: a report from the American Heart Association. Circulation 2017;135:e146-603.

2. Farías JG, Molina VM, Carrasco RA, et al. Antioxidant therapeutic strategies for cardiovascular conditions associated with oxidative stress. Nutrients 2017;9:966.

3. Rabinovich-Nikitin I, Lieberman B, Martino TA, et al. Circadian-regulated cell death in cardiovascular diseases. Circulation 2019;139:965-80.

4. Huang C, Wang Y, Li X, et al. Clinical features of patients infected with 2019 novel coronavirus in Wuhan, China. Lancet 2020;395:497-506.

5. Wang C, Horby PW, Hayden FG, et al. A novel coronavirus outbreak of global health concern. Lancet 2020;395:470-3.

6. Yang $\mathrm{X}, \mathrm{Yu} \mathrm{Y,} \mathrm{Xu} \mathrm{J,} \mathrm{et} \mathrm{al.} \mathrm{Clinical} \mathrm{course} \mathrm{and} \mathrm{outcomes}$ of critically ill patients with SARS-CoV-2 pneumonia in Wuhan, China: a single-centered, retrospective, observational study. Lancet Respir Med 2020;8:475-81.

7. Ruan Q, Yang K, Wang W, et al. Clinical predictors of mortality due to COVID-19 based on an analysis of data of 150 patients from Wuhan, China. Intensive Care Med 2020;46:846-8.

8. Babapoor-Farrokhran S, Gill D, Walker J, et al. Myocardial injury and COVID-19: possible mechanisms. Life Sci 2020;253:117723.

9. Zhang $\mathrm{Y}$, Zhang $\mathrm{Y}$, Jin $\mathrm{XF}$, et al. The role of astragaloside IV against cerebral ischemia/reperfusion injury: suppression of apoptosis via promotion of P62-LC3autophagy. Molecules 2019;24:1838.

10. Lai PK, Chan JY, Cheng L, et al. Isolation of antiinflammatory fractions and compounds from the root of Astragalus membranaceus. Phytother Res 2013;27:581-7.
11. Gui D, Huang J, Guo Y, et al. Astragaloside IV ameliorates renal injury in streptozotocin-induced diabetic rats through inhibiting NF-kB-mediated inflammatory genes expression. Cytokine 2013;61:970-7.

12. Huang XP, Tan H, Chen BY, et al. Astragalus extract alleviates nerve injury after cerebral ischemia by improving energy metabolism and inhibiting apoptosis. Biol Pharm Bull 2012;35:449-54.

13. Zhang ZG, Wu L, Wang JL, et al. Astragaloside IV prevents $\mathrm{MPP}^{+}$-induced $\mathrm{SH}-\mathrm{SY} 5 \mathrm{Y}$ cell death via the inhibition of Bax-mediated pathways and ROS production. Mol Cell Biochem 2012;364:209-16.

14. Zhang T, Wang H, Lu M, et al. Astragaloside IV prevents myocardial hypertrophy induced by mechanical stress by activating autophagy and reducing inflammation. Am J Transl Res 2020;12:5332-42.

15. Zhang DW, Bian ZP, Xu JD, et al. Astragaloside IV alleviates hypoxia/reoxygenation-induced neonatal rat cardiomyocyte injury via the protein kinase a pathway. Pharmacology 2012;90:95-101.

16. Luo Y, Wan Q, Xu M, et al. Nutritional preconditioning induced by astragaloside IV on isolated hearts and cardiomyocytes against myocardial ischemia injury via improving Bcl-2-mediated mitochondrial function. Chem Biol Interact 2019;309:108723.

17. Wang D, Liu Y, Zhong G, et al. Compatibility of Tanshinone IIA and Astragaloside IV in attenuating hypoxia-induced cardiomyocytes injury. J Ethnopharmacol 2017;204:67-76.

18. Ren S, Zhang H, Mu Y, et al. Pharmacological effects of Astragaloside IV: a literature review. J Tradit Chin Med 2013;33:413-6.

19. Li ZP, Cao Q. Effects of astragaloside IV on myocardial calcium transport and cardiac function in ischemic rats. Acta Pharmacol Sin 2002;23:898-904.

20. Sui YB, Wang Y, Liu L, et al. Astragaloside IV alleviates heart failure by promoting angiogenesis through the JAKSTAT3 pathway. Pharm Biol 2019;57:48-54.

21. Dales JP, Beaufils N, Silvy M, et al. Hypoxia inducible factor 1alpha gene (HIF-1alpha) splice variants: potential prognostic biomarkers in breast cancer. BMC Med 2010;8:44.

22. Lee SH, Wolf PL, Escudero R, et al. Early expression of angiogenesis factors in acute myocardial ischemia and infarction. N Engl J Med 2000;342:626-33.

23. Zhang Q, Guo D, Wang Y, et al. Danqi pill protects against heart failure post-acute myocardial infarction via HIF-1 $\alpha /$ PGC- $1 \alpha$ mediated glucose metabolism pathway. 
Front Pharmacol 2020;11:458.

24. Natarajan R, Salloum FN, Fisher BJ, et al. Hypoxia inducible factor-1 activation by prolyl 4-hydroxylase-2 gene silencing attenuates myocardial ischemia reperfusion injury. Circ Res 2006;98:133-40.

25. Ockaili R, Natarajan R, Salloum F, et al. HIF-1 activation attenuates postischemic myocardial injury: role for heme oxygenase-1 in modulating microvascular chemokine generation. Am J Physiol Heart Circ Physiol 2005;289:H542-8.

26. Szczepanek K, Chen Q, Derecka M, et al. Mitochondrialtargeted Signal transducer and activator of transcription 3 (STAT3) protects against ischemia-induced changes in the electron transport chain and the generation of reactive oxygen species. J Biol Chem 2011;286:29610-20.

27. Li J, Shen J, Wang Z, et al. ELTD1 facilitates glioma proliferation, migration and invasion by activating JAK/ STAT3/HIF-1 $\alpha$ signaling axis. Sci Rep 2019;9:13904.

28. Zhu J, Tang Y, Wu Q, et al. HIF-1 $\alpha$ facilitates osteocytemediated osteoclastogenesis by activating JAK2/STAT3 pathway in vitro. J Cell Physiol 2019;234:21182-92.

29. Yu N, Wu JL, Xiao J, et al. HIF-1 $\alpha$ regulates angiogenesis via Notch1/STAT3/ETBR pathway in trophoblastic cells. Cell Cycle 2019;18:3502-12.

30. Saad MAE, Fahmy MIM, Al-Shorbagy M, et al. Nateglinide exerts neuroprotective effects via downregulation of HIF-1 $\alpha /$ TIM-3 inflammatory pathway and promotion of caveolin-1 expression in the rat's hippocampus subjected to focal cerebral ischemia/ reperfusion injury. Inflammation 2020;43:401-16.

31. Wang Z, Li MY, Zhang ZH, et al. Panaxadiol inhibits programmed cell death-ligand 1 expression and tumour proliferation via hypoxia-inducible factor (HIF)-1 $\alpha$ and STAT3 in human colon cancer cells. Pharmacol Res 2020;155:104727.

32. Rane S, He M, Sayed D, et al. Downregulation of miR199a derepresses hypoxia-inducible factor-1alpha and Sirtuin 1 and recapitulates hypoxia preconditioning in cardiac myocytes. Circ Res 2009;104:879-86.

33. Huang FY, Xia TL, Li JL, et al. The bifunctional SDF1-AnxA5 fusion protein protects cardiac function after myocardial infarction. J Cell Mol Med 2019;23:7673-84.

34. Schindler C, Levy DE, Decker T. JAK-STAT signaling: from interferons to cytokines. J Biol Chem 2007;282:20059-63.

35. Lai IC, Lai GM, Chow JM, et al. Active fraction (HS7) from Taiwanofungus camphoratus inhibits AKT-mTOR, ERK and STAT3 pathways and induces CDK inhibitors in
CL1-0 human lung cancer cells. Chin Med 2017;12:33.

36. Zhang L, Liu Q, Lu L, et al. Astragaloside IV stimulates angiogenesis and increases hypoxia-inducible factor$1 \alpha$ accumulation via phosphatidylinositol 3-kinase/Akt pathway. J Pharmacol Exp Ther 2011;338:485-91.

37. van Hagen M, Overmeer RM, Abolvardi SS, et al. RNF4 and VHL regulate the proteasomal degradation of SUMOconjugated hypoxia-inducible factor-2alpha. Nucleic Acids Res 2010;38:1922-31.

38. Wang X, Chen T. CUL4A regulates endometrial cancer cell proliferation, invasion and migration by interacting with CSN6. Mol Med Rep 2021;23:23.

39. Olivas-Chacon CI, Mullins C, Solberg A, et al. Assessment of ischemic cardiomyopathy using cardiovascular magnetic resonance imaging: a pictorial review. J Clin Imaging Sci 2015;5:28.

40. R Amin D, Sink E, Narayan SP, et al. Nanomaterials for cardiac tissue engineering. Molecules 2020;25:5189.

41. Qu YZ, Li M, Zhao YL, et al. Astragaloside IV attenuates cerebral ischemia-reperfusion-induced increase in permeability of the blood-brain barrier in rats. Eur J Pharmacol 2009;606:137-41.

42. Cheng S, Yu P, Yang L, et al. Astragaloside IV enhances cardioprotection of remote ischemic conditioning after acute myocardial infarction in rats. Am J Transl Res 2016;8:4657-69.

43. Mao Q, Chen C, Liang H, et al. Astragaloside IV inhibits excessive mesangial cell proliferation and renal fibrosis caused by diabetic nephropathy via modulation of the TGF- $\beta 1 / \mathrm{Smad} / \mathrm{miR}-192$ signaling pathway. Exp Ther Med 2019;18:3053-61.

44. Kohlhauer M, Pell VR, Burger N, et al. Protection against cardiac ischemia-reperfusion injury by hypothermia and by inhibition of succinate accumulation and oxidation is additive. Basic Res Cardiol 2019;114:18.

45. Sala-Mercado JA, Wider J, Undyala VV, et al. Profound cardioprotection with chloramphenicol succinate in the swine model of myocardial ischemia-reperfusion injury. Circulation 2010;122:S179-84.

46. Veeranki S, Tyagi SC. Mdivi-1 induced acute changes in the angiogenic profile after ischemia-reperfusion injury in female mice. Physiol Rep 2017;5:e13298.

47. Wang JX, Jiao JQ, Li Q, et al. miR-499 regulates mitochondrial dynamics by targeting calcineurin and dynamin-related protein-1. Nat Med 2011;17:71-8.

48. Gao G, Chen W, Yan M, et al. Rapamycin regulates the balance between cardiomyocyte apoptosis and autophagy in chronic heart failure by inhibiting mTOR signaling. Int 
J Mol Med 2020;45:195-209.

49. Gong L, Chang H, Zhang J, et al. Astragaloside IV protects rat cardiomyocytes from hypoxia-induced injury by down-regulation of miR-23a and miR-92a. Cell Physiol Biochem 2018;49:2240-53.

50. Du J, Liu J, Zhen J, et al. Astragaloside IV protects cardiomyocytes from hypoxia-induced injury by downregulation of lncRNA GAS5. Biomed Pharmacother 2019;116:109028.

51. Jiang S, Jiao G, Chen Y, et al. Astragaloside IV attenuates chronic intermittent hypoxia-induced myocardial injury by modulating $\mathrm{Ca} 2+$ homeostasis. Cell Biochem Funct 2020;38:710-20.

52. Yang P, Zhou Y, Xia Q, et al. Astragaloside IV regulates the PI3K/Akt/HO-1 signaling pathway and inhibits $\mathrm{H} 9 \mathrm{c} 2$ cardiomyocyte injury induced by hypoxia-reoxygenation. Biol Pharm Bull 2019;42:721-7.

53. Wei $\mathrm{D}, \mathrm{Xu} \mathrm{H}$, Gai X, et al. Astragaloside IV alleviates myocardial ischemia-reperfusion injury in rats through regulating PI3K/AKT/GSK-3 $\beta$ signaling pathways. Acta Cir Bras 2019;34:e201900708.

54. Cheng S, Zhang X, Feng Q, et al. Astragaloside IV exerts angiogenesis and cardioprotection after myocardial infarction via regulating PTEN/PI3K/Akt signaling pathway. Life Sci 2019;227:82-93.

55. Hirota K. Hypoxia-inducible factor 1, a master transcription factor of cellular hypoxic gene expression. J Anesth 2002;16:150-9.

56. Strijdom H, Friedrich SO, Hattingh S, et al. Hypoxiainduced regulation of nitric oxide synthase in cardiac

Cite this article as: Li B, Yu J, Liu P, Zeng T, Zeng X. Astragaloside IV protects cardiomyocytes against hypoxia injury via $H I F-1 \alpha$ and the $7 A K 2 / S T A T 3$ pathway. Ann Transl Med 2021;9(18):1435. doi: 10.21037/atm-21-4080 endothelial cells and myocytes and the role of the PI3-K/ PKB pathway. Mol Cell Biochem 2009;321:23-35.

57. Huang LE, Arany Z, Livingston DM, et al. Activation of hypoxia-inducible transcription factor depends primarily upon redox-sensitive stabilization of its alpha subunit. J Biol Chem 1996;271:32253-9.

58. Zhang Y, Liu D, Hu H, et al. HIF-1 $\alpha /$ BNIP3 signaling pathway-induced-autophagy plays protective role during myocardial ischemia-reperfusion injury. Biomed Pharmacother 2019;120:109464.

59. Chen $X$, Wang C, Yang P, et al. Ube2s-stabilized $\beta$-catenin protects against myocardial ischemia/reperfusion injury by activating HIF- $1 \alpha$ signaling. Aging (Albany NY) 2020;12:5716-32.

60. Fuglesteg BN, Suleman N, Tiron C, et al. Signal transducer and activator of transcription 3 is involved in the cardioprotective signalling pathway activated by insulin therapy at reperfusion. Basic Res Cardiol 2008;103:444-53.

61. Meng X, Grötsch B, Luo Y, et al. Hypoxia-inducible factor- $1 \alpha$ is a critical transcription factor for IL-10producing B cells in autoimmune disease. Nat Commun 2018;9:251.

62. Qian T, Hong J, Wang L, et al. Regulation of CD11b by HIF- $1 \alpha$ and the STAT3 signaling pathway contributes to the immunosuppressive function of B cells in inflammatory bowel disease. Mol Immunol 2019;111:162-71.

(English Language Editor: C. Betlzar) 